\title{
Respostas produtivas, marginais e econômicas de vacas Girolando sob pastejo de Tifton 85 recebendo diferentes concentrados
}

\author{
[Productive, marginal and economic responses of Girolando cows under grazing of Tifton 85 \\ receiving different concentrates] \\ R.M.A. Teixeira ${ }^{1}$, L.F. Benfica ${ }^{2}$, K.C. Alessi ${ }^{3}$, E.A. Silva ${ }^{4}$, L.O. Fernandes ${ }^{4}$, A.S. Oliveira ${ }^{5}$, \\ D.J.G. Faria ${ }^{6}$, F.M. Salvador 6 \\ ${ }^{1}$ Instituto Federal do Sudeste de Minas Gerais - Rio Pomba, MG \\ ${ }^{2}$ Aluno de graduação - Instituto Federal do Triângulo Mineiro - Uberaba, MG \\ ${ }^{3}$ Aluno de pós-graduação - Universidade Federal do Mato Grosso - Cuiabá, MT \\ ${ }^{4}$ Pesquisador da Epamig - Uberaba, MG \\ ${ }^{5}$ Universidade Federal do Mato Grosso - Sinop, MT \\ ${ }^{6}$ Instituto Federal do Triângulo Mineiro - Uberaba, MG
}

\begin{abstract}
RESUMO
A energia é considerada o nutriente mais limitante para produção de leite de vacas em pastagens, mas será que a suplementação deve ser energética? Assim, objetivou-se avaliar a resposta produtiva, marginal e econômica de vacas Girolandas mantidas em pastagem de Tifton 85 durante o período das águas, as quais receberam diferentes tipos de suplementação. O primeiro tratamento foi a suplementação mineral ad libitum; o segundo tratamento, o fornecimento de $1,0 \mathrm{~kg} / \mathrm{dia}$ de suplementação proteica; o terceiro e quarto tratamentos, o fornecimento de $2,0 \mathrm{~kg} / \mathrm{dia}$ de suplementação proteico-energética e $4,0 \mathrm{~kg} / \mathrm{dia}$ de suplementação energética, respectivamente. Foram utilizadas 12 vacas com produção de leite média de $15,0 \pm 1,99 \mathrm{~kg} / \mathrm{dia}$. Os dados foram avaliados como três quadrados latinos 4 x 4 simultâneos ao nível de $5 \%$ de significância. O consumo de matéria seca de forragem não foi influenciado pelas suplementações $(\mathrm{P}>0,05)$. A maior produção de leite $(\mathrm{P}<0,05)$ foi observada com a suplementação energética, em média $14,73 \mathrm{~kg} / \mathrm{dia}$, não diferente da produção com a suplementação proteico-energética, média de $13,84 \mathrm{~kg}$ de leite/dia. Observaram-se respostas produtivas marginais de 1,$03 ; 0,84$ e $0,44 \mathrm{~kg}$ de leite/kg de concentrado, para suplemento proteico, proteico-energético e energético, respectivamente, bem como saldo financeiro positivo para as suplementações proteica e proteico-energética em relação à suplementação mineral. A suplementação proteico-energética mostrou-se a mais eficiente.
\end{abstract}

Palavras-chave: consumo, eficiência, energético, produção leiteira, proteico

\begin{abstract}
Energy is considered the most limiting nutrient for the production of milk cows in pastures, but will that supplementation must be energy? The objective was to evaluate the productive, marginal and economic response of Girolando cows kept in Tifton 85 pasture during rain period receiving different types of supplementation. One treatment was mineral supplementation ad libitum, a second treatment providing $1.0 \mathrm{~kg} /$ day of protein supplementation, and a third and fourth treatments providing $2.0 \mathrm{~kg} /$ day of proteinenergetic supplementation and $4.0 \mathrm{~kg} /$ day of energy supplementation, respectively. Twelve cows were used with average milk production $15.0 \pm 1.99 \mathrm{~kg} /$ day. The data were evaluated as three Latin squares $4 \times 4$ simultaneous to the $5 \%$ level of significance. The dry matter intake of forage not influenced by supplementation $(P>0.05)$. The higher milk production was observed with energetic supplementation on average $14.73 \mathrm{~kg}$ of milk/day, no different of production obtained from protein-energy supplementation, average of $13.84 \mathrm{~kg}$ of milk/day. Marginal productive response was observed, with responses of 1.03; 0.84 and $0.44 \mathrm{~kg}$ milk/kg concentrate for proteic supplement, proteic-energetic, and energetic, respectively.
\end{abstract}

Recebido em 25 de abril de 2017

Aceito em 31 de outubro de 2017

E-mail: rafael.teixeira@ifsudestemg.edu.br 
Positive financial balance was found for protein and protein-energy supplements in relation to mineral supplementation. Protein-energy supplementation proved the most efficient.

Keywords: intake, efficiency, energetic, dairy production, proteic

\section{INTRODUÇÃO}

As pastagens de clima temperado se distinguem das tropicais por proporcionarem maior produção por animal, em razão do maior consumo voluntário, possibilitado pela maior digestibilidade dos nutrientes e pelo maior teor de proteína bruta, o que propicia produções individuais médias de 22kg/vaca/dia (Bargo et al., 2003). Já no desempenho individual de vacas em pastagens tropicais, observam-se médias entre 9 a 13kg/vaca/dia, em razão da menor consumo voluntário de matéria seca. $\mathrm{O}$ grande potencial de fixação de carbono em compostos estruturais de menor taxa de digestão e a alta eficiência de utilização de nitrogênio, que, por efeito de diluição reduz os teores de nitrogênio nas forrageiras tropicais, ajudam a explicar essas diferenças (Borges et al., 2015).

Com o objetivo de se ajustarem dietas de vacas leiteiras a pasto, diversos autores afirmam que a energia é o nutriente mais limitante em pastagem de gramíneas tropicais (Reever et al., 1996; Gomide, 1998) e em pastagens temperadas (Bargo et al., 2003). Entretanto, segundo informações levantadas por Detmann et al. (2014b), provindas de 44 experimentos com bovinos de corte no Brasil, existe um desequilíbrio nutricional nas pastagens tropicais durante a estação chuvosa, que se caracteriza por um excesso relativo de energia em relação à proteína. Nesses casos, a suplementação proteica se faz necessária para equilibrar a dieta basal e melhorar a utilização da energia metabolizável e da proteína metabolizável (Detmann et al., 2014a).

Por outro lado, a suplementação essencialmente energética conduziria o animal ao desconforto metabólico por excesso relativo de energia metabolizável, levando esse animal a substituir grande massa de forragem por pequena massa de suplemento, a fim de adequar-se à condição de conforto (Costa et al., 2011).

Assim, surgem dúvidas sobre que tipo de concentrado utilizar para vacas de leite a pasto no período das águas, já que essas novas teorias foram elaboradas com bovinos de corte.

Além disso, há dúvidas quanto à eficiência de utilização dessas suplementações concentradas. Isso porque, segundo Oliveira et al. (2010), as recomendações de suplementação deveriam ser dirigidas pela resposta animal, objetivando-se, portanto, a utilização econômica e ambiental mais eficiente dos nutrientes.

Dessa forma, objetivou-se avaliar a resposta produtiva, marginal e financeira de vacas da raça Girolando mantidas em pastagem de Tifton 85, sob lotação contínua, durante o período das águas, as quais receberam suplementação mineral, proteica, proteico-energética e energética.

\section{MATERIAL E MÉTODOS}

O presente trabalho foi desenvolvido no setor de Bovinocultura do Instituto Federal do Triângulo Mineiro, campus Uberaba (IFTM - Uberaba), localizado no município de Uberaba/MG. O período experimental foi de 10 de dezembro de 2014 a 11 de fevereiro de 2015, totalizando 63 dias de experimento durante o período das águas. $\mathrm{O}$ experimento foi submetido à Comissão de Ética no Uso de Animais do Instituto Federal de Educação, Ciência e Tecnologia do Triângulo Mineiro (Ceua/IFTM), com protocolo n ${ }^{\circ} 14 / 2014$, que emitiu o parecer: APROVADO.

Foram utilizadas 12 vacas da raça Girolando em lactação, com peso médio de $519,0 \pm 38,0 \mathrm{~kg}$ e produção de leite média de $15,0 \pm 1,99 \mathrm{~kg}$ por dia no início do experimento. Os animais foram distribuídos em três quadrados latinos $(4 \times 4)$, balanceados de acordo com o período de lactação, com 58, 90 e 141 dias de lactação. O experimento foi constituído de quatro períodos experimentais, com duração de 15 dias cada, sendo os primeiros 10 dias para adaptação dos animais aos tratamentos e cinco dias para coleta.

Os animais receberam quatro formas de suplementação concentrada, caracterizando os diferentes tratamentos, sendo uma 
suplementação testemunha, em que as vacas receberam apenas suplemento mineral $\mathrm{e}$ as quantidades de 1,$0 ; 2,0$ e 4,0kg/animal/dia de concentrado proteico, proteico-energético e energético, respectivamente. Os concentrados foram formulados para atender as exigências de uma vaca de $520 \mathrm{~kg}$, que produzia $15,0 \mathrm{~kg}$ de leite por dia e consumia por volta de $14 \mathrm{~kg}$ de matéria seca/dia, sendo esse animal mantido sob pastagem de Tifton 85 nas águas, conforme NRC (Nutrient..., 2001). Dessa forma, com as diferentes formulações e quantidades, garantiram-se as mesmas ingestões de farelo de soja, ureia e sal mineral, variando somente a ingestão milho moído, ou seja, ingrediente energético. Os animais receberam o concentrado duas vezes ao dia, metade da quantidade determinada em cada tratamento após as ordenhas da manhã (nove às 10 horas) e a outra metade após as ordenhas da tarde (16 às 17 horas). Na Tab. 1, encontram-se as fórmulas dos concentrados utilizados no experimento.

Tabela 1. Composição percentual dos ingredientes utilizados nos diferentes tipos de concentrados

\begin{tabular}{ccccc}
\hline \multicolumn{5}{c}{ Tipos de suplementação } \\
\hline Composição & Sal mineral & Proteica & Proteico-energética & Energética \\
\hline Milho moído (\%) & - & 54,0 & 77,5 & 88,5 \\
Farelo de soja (\%) & - & 35,0 & 17,0 & 9,0 \\
Ureia (\%) & - & 7,0 & 3,5 & 1,5 \\
Sal mineral (\%)* & 100 & 4,0 & 2,0 & 1,0
\end{tabular}

* Níveis de garantia por kg de produto: cálcio - 130 a 185g; fósforo - 90g; sódio - 110g; enxofre - 25g; zinco 4500mg; cobre - 1000mg; cobalto - 80mg; iodo - 60mg; selênio - $22 \mathrm{mg}$.

Entre as ordenhas e no período da noite, os animais tiveram livre acesso ao piquete de Tifton 85 (Cynodon dactylon (L) Pers. cv. Tifton 85), com área de 5,28 hectares para todos os animais, provido de bebedouro, cocho de saleiro e sombrite. O sistema adotado foi de pastejo contínuo, com a disponibilidade média de forragem de $4.558,00 \mathrm{~kg}$ de matéria seca por hectare (kg de MS/ha). A avaliação da biomassa de forragem foi realizada em cada período experimental, mediante amostragem, por meio do corte ao nível do solo de toda a forragem contida em uma moldura de metal com 0,5 x $0,5 \mathrm{~m}$ de área. A estimativa do valor nutricional da forragem foi feita pelo uso da técnica de pastejo simulado, observando-se o hábito de pastejo dos animais.

A excreção da matéria seca fecal foi estimada utilizando-se o indicador externo, dióxido de titânio, sendo calculada com base na razão entre a quantidade do indicador fornecido e sua concentração nas fezes (Oliveira et al., 2012). Para tal, o dióxido de titânio foi fornecido aos animais na dosagem de $20,0 \mathrm{~g} / \mathrm{dia}$, durante sete dias consecutivos por período experimental. O indicador externo foi acondicionado em cartuchos de papel e introduzido na boca do animal, sempre após a ordenha da manhã e antes do fornecimento de concentrado. Já a coleta de fezes foi feita durante quatro dias consecutivos por período experimental, quando foram obtidas amostras compostas por animal por período, e teve início cinco dias após a introdução do fornecimento de dióxido de titânio.

As amostras de pastejo simulado do Tifton 85 , suplemento concentrado e fezes foram pré-secas em estufas de ventilação forçada a $65^{\circ} \mathrm{C}$, durante 72 horas. Em seguida, foram homogeneizadas e moídas em moinho tipo Willey, utilizando-se peneira com malha de $1 \mathrm{~mm}$. As análises de matéria seca (MS), matéria orgânica (MO), compostos nitrogenados totais, fibra em detergente neutro (FDN), fibra em detergente ácido (FDA), lignina, extrato etéreo (EE), compostos nitrogenados insolúveis em detergente neutro (NIDN), $\mathrm{N}$ insolúveis em detergente ácido (NIDA) e minerais foram realizadas segundo os procedimentos descritos por Silva e Queiroz (2002). Os compostos nitrogenados não proteicos foram determinados conforme recomendações de Licitra et al. (1996), enquanto os teores de carboidratos totais $(\mathrm{CHO})$ foram calculados de acordo com Sniffen et al. (1992): $\mathrm{CHO}=100-(\% \mathrm{~PB}+\% \mathrm{EE}+\%$ Cinzas $)$, sendo os teores de carboidratos não fibrosos $(\mathrm{CNF})$ obtidos pela fórmula $\mathrm{CNF}=100-(\% \mathrm{~PB}$ 
$+\% \mathrm{EE}+\%$ CINZAS + FDNpb). Na Tab. 2, é apresentada a composição bromatológica média do Tifton 85 e dos concentrados utilizados no experimento.

Tabela 2. Composição bromatológica do Tifton 85 e dos concentrados (\% MS)

\begin{tabular}{ccccc}
\hline Itens & Tifton 85 & Proteico & Proteico-energético & Energético \\
\hline Matéria seca total & 36,62 & 90,00 & 90,00 & 90,00 \\
Matéria orgânica & 30,71 & 82,26 & 85,21 & 86,64 \\
Proteína bruta & 9,10 & 44,62 & 26,54 & 17,20 \\
Extrato etéreo & 0,74 & 3,15 & 3,83 & 4,16 \\
Matéria mineral & 5,92 & 7,73 & 4,78 & 3,36 \\
Fibra em detergente neutro & 76,85 & 14,50 & 14,97 & 15,27 \\
PIDN1 $^{1}$ & 19,82 & 4,10 & 4,60 & 4,88 \\
FDNi & 33,97 & - & - & - \\
Fibra em detergente ácido & 31,37 & 6,08 & 5,23 & 64,92 \\
Carboidratos não fibrosos & 14,37 & 34,05 & 54,48 & 75,31 \\
Carboidratos totais & 84,27 & 44,50 & 64,84 & 85,18 \\
Nutrientes digestíveis totais & 50,04 & 80,00 & 83,53 & \\
\hline
\end{tabular}

${ }^{1} \mathrm{PIDN}$ - proteína indigestível em detergente neutro; ${ }^{2} \mathrm{FDNi}$ - fibra em detergente neutro indigestível.

A fibra em detergente neutro indigestível (FDNi) foi utilizada como indicador interno para estimar o consumo de matéria seca, adotando-se a metodologia descrita por Detmann et al. (2001). Assim, estabeleceu-se a relação entre a ingestão diária do indicador interno (FDNi) no concentrado mais forragem e sua concentração nas

fezes:

$$
C M S=\frac{(E F x C I F)-I C}{C I F O}+C M S C \text {, em que: }
$$

$\mathrm{EF}=$ excreção fecal (kg/dia); CIF = concentração do indicador interno nas fezes $(\mathrm{kg} / \mathrm{kg})$; IC = indicador interno presente no concentrado $(\mathrm{kg} / \mathrm{dia}) ; \mathrm{CIFO}=$ concentração do indicador interno na forragem $(\mathrm{kg} / \mathrm{kg})$ e CMSC = consumo de matéria seca de concentrado ( $\mathrm{kg} / \mathrm{dia})$.

As vacas foram ordenhadas mecanicamente, duas vezes ao dia, e, por meio de dispositivo acoplado à ordenhadeira mecânica, foi feita a pesagem do leite nos dois últimos dias de cada período experimental. Foram coletadas amostras de leite, sendo estas acondicionadas em frascos plásticos com conservantes (Bronopol®), mantidas entre 2 e $6^{\circ} \mathrm{C}$, e encaminhadas para o Laboratório de Análises de Qualidade de Leite da Embrapa Gado de Leite, no município de Juiz de Fora MG, para fins de análises dos teores de proteína bruta, gordura, lactose, extrato seco total e contagem de células somáticas. A produção de leite corrigida (PLC) para 3,5\% de gordura foi calculada segundo Sklan et al. (1992), pela seguinte fórmula: $\mathrm{PLC}=(0,432+0,1625 \times \%$ gordura do leite) $\times$ produção de leite em $\mathrm{kg} /$ dia .
A resposta produtiva foi estimada pela diferença entre a produção de leite das vacas que receberam suplementação mineral e a produção leite das vacas que receberam suplementação concentrada, sendo essa diferença dividida pela quantidade de concentrado consumido, ou seja, 1,0; 2,0 e 4,0kg de concentrado, respectivamente. $\mathrm{E}$ a resposta produtiva marginal (RPMa), que considera o incremento do produto animal, foi obtida pela diferença da produção de leite e do consumo de concentrado em relação ao nível imediatamente anterior a este, e não ao controle (suplementação apenas mineral, por exemplo), segundo Oliveira et al. (2010).

Para estimativas da avaliação financeira, obtevese o preço de um dólar durante o período experimental, que foi, em média, de $\mathrm{R} \$ 2,68$. Assim, o preço do litro de leite foi, em média, de U\$ 0,37/litro, de acordo com a indústria que captava leite no IFTM, campus Uberaba. Na determinação do custo final do concentrado, todos os componentes presentes neste foram orçados em três lojas agropecuárias, no município de Uberaba/ MG, com média por quilo de U\$ 0,26 para milho moído, U\$ 0,46 para farelo de soja, U\$ 0,49 para ureia e U\$ 0,56 para suplemento mineral. Para a determinação do custo de uso da pastagem, foi adotado como referência o preço de aluguel/mês/animal na região, com média de U\$ 9,33 mês/animal. 
No último dia de cada período experimental, foram feitas observações visuais para a determinação do escore de condição corporal (ECC) dos animais e efetuou-se a pesagem para determinação do peso vivo (PV) individual.

Os dados foram analisados como três quadrados latinos 4 x 4 simultâneos, em que: Yijkl $=\mu+$ Qi $+\mathrm{Tj}+(\mathrm{P} / \mathrm{Q}) \mathrm{ik}+(\mathrm{V} / \mathrm{Q}) \mathrm{il}+\mathrm{QxTij}+$ eijkl,

em que: $Y$ ijkl= observação na vaca 1 , no período $\mathrm{k}$, submetida ao tratamento $\mathrm{j}$, no quadrado latino i; $\mu=$ média geral; $\mathrm{Q} i=$ efeito aleatório do quadrado latino $i$, sendo $i=1,2,3 ; \mathrm{Tj}=$ efeito fixo do tratamento $j$, sendo $j=1,2,3,4$; $(P / Q) i k=$ efeito aleatório do período $\mathrm{k}$, dentro do quadrado latino $\mathrm{i}$, sendo $\mathrm{k}=1,2,3,4$; (V/Q)il= efeito aleatório da vaca 1 , dentro do quadrado latino $\mathrm{i}$, sendo $1=1,2$, 3, 4; QxTij= efeito aleatório de interação entre o quadrado latino i e o tratamento $\mathrm{j}$; eeijkl = erro aleatório, associado a cada observação, pressuposto NID $(0 ; \sigma 2)$. O efeito do tipo de suplementação concentrada foi submetido ao teste de média de Tukey pelo programa SISVAR (Ferreira, 2011). Adotou-se nível de 0,05 de probabilidade para o erro tipo I.

\section{RESULTADOS E DISCUSSÃO}

A massa de forragem para os quatro períodos experimentais foi de 4883,0;4746,0; 4935,0 e $3668,0 \mathrm{~kg} / \mathrm{ha}$ de matéria seca, em relação à oferta de forragem referente ao peso vivo animal. As disponibilidades foram de 27,60\%; 26,82\%; $27,89 \%$ e $20,73 \%$ do peso vivo, também para os quatro períodos experimentais, respectivamente. Esses valores demonstram que não houve restrição de forragem para o período analisado, pois, segundo Almeida et al. (2000), quando a oferta de forragem é superior a $14 \%$ do PV, pode ocorrer grande desperdício de forragem associado à alta quantidade de material senescente presente na pastagem, o qual pode afetar o desempenho animal.

Nenhum tipo de suplementação proporcionou efeito substitutivo da forragem, sendo observados consumos de forragem similares para todos os tipos de suplementação (Tab. 3). Geralmente quando se utilizam suplementos concentrados em adição à dieta com pastagem, há ocorrência de efeito substitutivo, principalmente em elevado nível de concentrado, em que o aumento no consumo deste reduz o consumo de pasto de 0,32 a $0,40 \mathrm{~kg}$ de matéria seca de pasto por $\mathrm{kg}$ de concentrado utilizado (Bargo et al., 2003; Santos et al., 2008).

Tabela 3. Consumos em kg/dia de matéria seca de concentrado, forragem, matéria seca total (CMS total), consumo de matéria seca por dia em percentual do peso vivo (CMS \% PV), consumo diário de proteína bruta (CPB), consumo diário de nutrientes digestíveis totais (CNDT) e digestibilidade da matéria seca total (DMS)

\begin{tabular}{|c|c|c|c|c|c|c|}
\hline \multirow[b]{2}{*}{ Item } & \multicolumn{4}{|c|}{ Tipos de suplementação } & \multirow[b]{2}{*}{ EPM } & \multirow[b]{2}{*}{$\mathrm{P}$} \\
\hline & Sal mineral & Proteica & $\begin{array}{l}\text { Proteico- } \\
\text { energética }\end{array}$ & Energética & & \\
\hline $\begin{array}{l}\text { Consumo } \\
\text { concentrado }\end{array}$ & 0 & 0,91 & 1,81 & 3,62 & - & - \\
\hline $\begin{array}{l}\text { Consumo de } \\
\text { forragem }\end{array}$ & 11,35 & 10,1 & 11,04 & 10,97 & 0,74 & 0,6737 \\
\hline CMS total & $11,35 \mathrm{a}$ & $11,00 \mathrm{a}$ & $12,85 \mathrm{ab}$ & $14,59 \mathrm{~b}$ & 0,74 & 0,0124 \\
\hline CMS \% PV & $2,19 a b$ & $2,17 \mathrm{a}$ & $2,46 \mathrm{ab}$ & $2,81 \mathrm{~b}$ & 0,16 & 0,0319 \\
\hline $\mathrm{CPB}$ & $1,02 \mathrm{a}$ & $1,31 \mathrm{~b}$ & $1,48 \mathrm{bc}$ & $1,62 \mathrm{c}$ & 0,063 & 0,0001 \\
\hline CNDT & $5,68 \mathrm{a}$ & $5,78 \mathrm{a}$ & $7,03 \mathrm{a}$ & $8,57 \mathrm{~b}$ & 0,37 & 0,0001 \\
\hline DMS & $32,07 \mathrm{a}$ & $37,45 \mathrm{a}$ & $40,50 \mathrm{bc}$ & $44,05 \mathrm{c}$ & 1,10 & 0,0001 \\
\hline
\end{tabular}

Médias na mesma linha seguidas por mesma letra minúscula não diferem entre si ao nível de 5,0\% de significância pelo teste de Tukey; EPM = erro-padrão da média; $\mathrm{P}=$ probabilidade.

A grande maioria das pastagens manejadas em lotação contínua durante o período das águas, enquanto dieta completa, apresenta excesso relativo de energia em relação à proteína. Nessas circunstâncias, a suplementação energética forçaria ainda mais o desequilíbrio na razão energia/proteína bruta (NDT/PB) (Costa et al., 2011). 
Pelo pressuposto, nas condições avaliadas, era de se esperar que houvesse uma redução de consumo de forragem, devido à suplementação energética, e um aumento de consumo de forragem, devido à suplementação proteica, quadro não verificado em nenhuma das situações. $\mathrm{O}$ que se verificou foi um aumento no consumo de matéria seca total $(\mathrm{P}<0,05)$ dos animais que receberam suplementação energética (Tab. 3).

Uma possível explicação para essa situação seria a quantidade de suplementação utilizada, o que poderia ter mantido uma relação energia:proteína ainda adequada, evitando-se efeitos substitutivos. Isso porque, ao se utilizarem os diferentes tipos de concentrado, garantiu-se a mesma ingestão de farelo de soja, ureia e sal mineral, mas aumentou-se a ingestão de milho moído, que, de modo geral, aumentou a quantidade de energia ingerida, porém, em menor proporção, também aumentou a quantidade de proteína bruta ingerida, mantendo a relação energia:proteína adequada.

Assim, segundo o NRC (Nutrient..., 2001), os animais do presente trabalho demandam, em média, uma dieta com relação NDT/PB de 4,55 de exigência para mantença e produção. Além disso, ao se avaliar o consumo de NDT e de PB (Tab. 3), observa-se uma relação NDT/PB em valores de 5,56; 4,41; 4,75 e 5,29, para os tipos de suplementação com sal mineral, proteica, proteico-energética e energética, respectivamente. Com isso, verifica-se que a relação NDT/PB da dieta com suplementação energética foi próxima a dos animais que receberam apenas sal mineral, talvez sendo essa uma das possíveis explicações para o consumo de forragem não ter sido influenciado, aumentando-se apenas o consumo de matéria seca total.

De acordo com Figueiras et al. (2015), a inclusão de compostos nitrogenados suplementares na dieta de bovinos alimentados com gramíneas tropicais pode ampliar o consumo de forragem basal até que níveis proteicos próximos a $100 \mathrm{~g} / \mathrm{kg}$ MS sejam atingidos. Dessa forma, verificou-se um consumo de 89,$9 ; 119,1 ; 115,2$; $111,0 \mathrm{~g} / \mathrm{kg} \mathrm{MS}$, para dietas com suplemento mineral, com suplementação proteica, proteico- energética e energética, respectivamente. Ou seja, o aporte de proteína foi similar entre as dietas, o que poderia também justificar a ausência de efeito no consumo de forragem e o incremento no consumo de matéria seca total. Já segundo Detmann et al. (2014b), o consumo voluntário de forragem tem sido estimulado com o estabelecimento de concentrações de proteínas próximas a $145 \mathrm{~g} / \mathrm{kg}$ MS e de nitrogênio amoniacal no rúmen (NAR) próximas a $15 \mathrm{mg} / \mathrm{dL}$ (Detmann et al., 2009).

O uso da suplementação concentrada proporcionou diferentes produções de leite em $\mathrm{kg} / \mathrm{dia} \quad(\mathrm{P}<0,05)$. Os animais que receberam apenas suplemento mineral produziram, em média, 11,97kg de leite/dia (Tab. 4). A pastagem de Tifton 85 no período das águas, manejada sob lotação contínua, garante uma produção de leite adequada e superior à média das forrageiras tropicais, já que, segundo Oliveira et al. (2010), o potencial de produção de leite de forrageiras tropicais sem suplementação com concentrado seria por volta de $10,554 \mathrm{~kg} / \mathrm{dia}$. A maior produção de leite foi verificada com a suplementação energética, em média, $14,73 \mathrm{~kg}$ de leite/dia, não sendo diferente da produção obtida com a suplementação proteico-energética, que ficou, em média, com uma produção diária de $13,84 \mathrm{~kg}$ de leite. Como o consumo de matéria seca de forragem foi igual, entende-se que o critério que irá definir a suplementação mais adequada será a eficiência econômica de utilização do concentrado.

Nesse sentido, a RPMa decresce com o aumento na quantidade de suplementos ofertados aos animais, sendo uma resposta de natureza biológica e um reflexo da saturação dos sistemas enzimáticos. Assim, verifica-se que a resposta biológica (RPMa) é maximizada nos menores níveis de suplementação, o que, necessariamente, não garante máxima eficiência econômica. A eficiência econômica (saldo com suplementação) máxima é obtida naquela quantidade de suplemento cuja RPMa se iguala à razão preço do suplemento (Px)/preço do produto animal (Py); portanto, a razão Px/Py é que define a quantidade ótima de suplementos (Oliveira, 2015). 
Tabela 4. Produção de leite (PL), resposta produtiva, marginal e PL corrigida para gordura de vacas Girolando recebendo diferentes tipos de suplementação no período das águas

\begin{tabular}{|c|c|c|c|c|c|c|}
\hline \multirow[b]{2}{*}{ Item } & \multicolumn{4}{|c|}{ Tipos de suplementação } & \multirow[b]{2}{*}{ EPM } & \multirow[b]{2}{*}{$\mathrm{P}$} \\
\hline & $\begin{array}{c}\text { Sal } \\
\text { mineral }\end{array}$ & Proteica & $\begin{array}{l}\text { Proteico- } \\
\text { energética }\end{array}$ & Energética & & \\
\hline Produção de leite, kg/dia & $11,97 \mathrm{c}$ & $\begin{array}{c}13,00 \\
b c\end{array}$ & $13,84 \mathrm{ab}$ & $14,73 \mathrm{a}$ & 0,33 & $<0,0001$ \\
\hline Resposta produtiva $^{1}$ & - & 1,03 & 0,93 & 0,69 & - & - \\
\hline $\begin{array}{l}\text { Reposta produtiva marginal } \\
(\mathrm{RPMa})^{2}\end{array}$ & - & 1,03 & 0,84 & 0,44 & - & - \\
\hline $\begin{array}{c}\text { PL corrigida } 3,5 \% \text { de gordura, } \\
\mathrm{kg} / \mathrm{dia}\end{array}$ & 12,7 & 13,25 & 13,87 & 14,02 & 0,57 & 0,3505 \\
\hline Resposta produtiva $^{3}$ & - & 0,55 & 0,585 & 0,33 & - & - \\
\hline $\begin{array}{l}\text { Reposta produtiva marginal } \\
(\mathrm{RPMa})^{3}\end{array}$ & - & 0,55 & 0,62 & 0,075 & - & - \\
\hline
\end{tabular}

${ }^{1}$ Diferencial de produção de leite/diferencial de consumo de concentrado (CCON) na matéria seca nas quantidades de 1,$0 ; 2,0$ e 4,0kg/dia em relação à dieta controle (sal mineral).

${ }^{2}$ Diferencial de produção de leite/diferencial de consumo de concentrado na matéria seca nas quantidades de 1,$0 ; 2,0$ e 4,0kg/dia em relação ao nível de suplementação anterior.

${ }^{3}$ Respostas produtivas e marginais em função de PL corrigida para 3,5\% de gordura.

Médias na mesma linha seguidas por mesma letra minúscula não diferem entre si ao nível de 5,0\% de significância pelo teste de Tukey; $\mathrm{EPM}=$ erro-padrão da média; $\mathrm{P}=$ probabilidade.

A RPMa foi de 1,03; 0,84 e 0,44kg de leite $/ \mathrm{kg}$ de suplemento, para suplemento proteico, proteicoenergético e energético, respectivamente (Tab. 4). As suplementações proteico-energética e energética proporcionaram a mesma produção de leite, porém a RPMa, na suplementação proteicoenergética, foi superior à suplementação energética, o que a torna mais apta a ser utilizada quando se almeja, além de resultados produtivos, uma maior eficiência econômica. Como a RPMa da suplementação proteico-energética foi de $0,84 \mathrm{~kg}$ de leite $/ \mathrm{kg}$ de suplemento, estimando-se o preço do leite a U\$ 0,37/litro, o preço do quilo de suplemento proteico-energético poderia ser de até U\$ 0,31/kg $(\mathrm{RPMa}=\mathrm{Px} / \mathrm{Py} \rightarrow 0,84=\mathrm{Px} / 0,37$ $\rightarrow \mathrm{Px}=0,84 * 0,37 \rightarrow \mathrm{Px}=0,31)$, o que justificaria seu uso na suplementação de vacas leiteiras no período das águas. Já para a suplementação energética, que obteve uma RPMa de $0,44 \mathrm{~kg}$ de leite $/ \mathrm{kg}$ de suplemento, o suplemento energético deveria custar, no máximo, U\$ $0,16 / \mathrm{kg}$, ou seja, uma diferença $50 \%$ a menos em relação à suplementação proteico-energética.

Avaliando-se a produção de leite corrigida para $3,5 \%$ de gordura, verifica-se que não houve diferença significativa $(\mathrm{P}>0,05)$ entre os diferentes tipos de suplementações (Tab 4). Esses resultados chamam a atenção para a baixa eficiência da suplementação de vacas mantidas a pasto durante o período das águas. Além disso, quando se avaliam as respostas produtivas e marginais do uso de suplemento em relação à produção de leite corrigida para gordura, observa-se maior eficiência da suplementação proteico-energética.

Ao se estimar o saldo financeiro (Tab. 5), dado pelo faturamento menos $o$ gasto com alimentação, as conclusões são exatamente as mesmas às obtidas com a avaliação da RPMa. A suplementação energética foi a que trouxe menor saldo, dado pela quantidade de concentrado nessa estratégia alimentar, obtendo-se saldo financeiro relativo negativo de $0,37 \%$, quando comparado à suplementação mineral. Por outro lado, a avaliação financeira confirma a hipótese de que a suplementação de vacas leiteiras sob pastagem no período das águas, sob lotação contínua, deve ser proteica e ou proteicoenergética e com menores quantidades de concentrados utilizados, obtendo-se saldo financeiro relativo de 2,60 e 3,86\%, respectivamente (Tab. 5). Essa avaliação financeira positiva para os suplementos proteico e proteico-energético, inclusive, vai de encontro ao preço estimado por $\mathrm{kg}$ de suplemento conforme a RPMa. 
Tabela 5. Saldo financeiro diário e relativo da produção de leite de vacas recebendo diferentes tipos de suplementação no período das águas

\begin{tabular}{ccccc} 
& Sal mineral & Proteica & Proteico- energética & Energética \\
\hline Custo suplemento (U\$/kg) & 0,56 & 0,36 & 0,31 & 0,28 \\
Consumo suplemento (kg/dia) & 0,15 & 1,00 & 2,00 & 4,00 \\
Custo diário com suplemento (U\$/dia) & 0,08 & 0,36 & 0,62 & 1,12 \\
Custo diário com forragem (U\$/dia) & 0,31 & 0,31 & 0,31 & 0,31 \\
Custo total diário com alimentação (U\$/dia) & 0,39 & 0,67 & 0,93 & 1,43 \\
Produção de leite (kg/dia) & 11,97 & 13,00 & 13,84 & 14,73 \\
Preço do leite (U\$/litro) & 0,37 & 0,37 & 0,37 & 0,37 \\
Receita com leite (U\$/dia) & 4,43 & 4,81 & 5,12 & 5,45 \\
Saldo financeiro diário (U\$/dia) & 4,03 & 4,14 & 4,19 & 4,02 \\
Saldo financeiro relativo (\%) & 100,00 & 102,60 & 103,86 & 99,63 \\
\hline
\end{tabular}

${ }^{1}$ Receita com leite - custo total diário com alimentação.

A proposta de se utilizar um suplemento proteico-energético fornecido em menores quantidades para vacas de leite sob pastagem no período das águas ainda é consolidada pela variação de peso vivo e pelo escore de condição corporal, os quais foram positivos e semelhantes aos dos animais que consumiram $4,0 \mathrm{~kg}$ de suplemento energético.

Com relação à composição do leite, os animais que receberam o concentrado energético foram os que produziram menor teor de gordura no leite
(Tab. 6). Isso pode ser explicado devido ao fato de rações com níveis elevados de concentrado provocarem redução no $\mathrm{pH}$ ruminal mediante o aumento dos ácidos orgânicos provenientes da fermentação dos carboidratos fermentáveis no rúmen. A queda do $\mathrm{pH}$ ruminal reduz imediatamente a lipólise e a bio-hidrogenação ruminal dos ácidos graxos e aumenta o fluxo de ácidos graxos insaturados trans-C18:1 para a glândula mamária, reduzindo a síntese de gordura do leite (Palmquist et al., 1993).

Tabela 6. Composição do leite de vacas da raça Girolando recebendo diferentes tipos de suplementação concentrada durante o período das águas

\begin{tabular}{|c|c|c|c|c|c|c|}
\hline \multirow[b]{2}{*}{ Item } & \multicolumn{4}{|c|}{ Tipos de suplementação } & \multirow[b]{2}{*}{ EPM } & \multirow[b]{2}{*}{$\mathrm{P}$} \\
\hline & Sal mineral & Proteica & $\begin{array}{l}\text { Proteico- } \\
\text { energética }\end{array}$ & Energética & & \\
\hline Gordura (\%) & $3,86 \mathrm{a}$ & $3,65 \mathrm{ab}$ & $3,51 \mathrm{ab}$ & $3,20 \mathrm{~b}$ & 0,13 & 0,0145 \\
\hline Proteína $(\%)$ & 3,29 & 3,20 & 3,28 & 3,26 & 0,05 & 0,5985 \\
\hline Lactose (\%) & $4,37 \mathrm{ab}$ & $4,28 \mathrm{~b}$ & $4,48 \mathrm{a}$ & $4,35 \mathrm{ab}$ & 0,04 & 0,0227 \\
\hline Extrato seco $(\%)$ & 12,48 & 12,06 & 12,24 & 11,76 & 0,18 & 0,0728 \\
\hline $\begin{array}{c}\text { Extrato seco } \\
\text { desengordurado }(\%)\end{array}$ & $8,62 \mathrm{ab}$ & $8,41 \mathrm{~b}$ & $8,73 \mathrm{a}$ & $8,56 \mathrm{ab}$ & 0,08 & 0,0680 \\
\hline $\begin{array}{c}\text { Contagem de células } \\
\text { somáticas (x } 1000 \\
\text { CCS/mL) }\end{array}$ & $256 \mathrm{~b}$ & $526 \mathrm{a}$ & $226 \mathrm{~b}$ & $223 \mathrm{~b}$ & 58,2 & 0,0041 \\
\hline Ureia $(\mathrm{mg} / \mathrm{dL})$ & $17,21 \mathrm{~b}$ & $21,01 \mathrm{a}$ & $21,28 \mathrm{a}$ & $16,57 \mathrm{~b}$ & 0,83 & 0,0008 \\
\hline
\end{tabular}

Médias na mesma linha seguidas por mesma letra minúscula não diferem entre si ao nível de 5,0\% de significância pelo teste de Tukey; $\mathrm{EPM}=$ erro-padrão da média; $\mathrm{P}=$ probabilidade; $\mathrm{PL}=$ produção de leite.

Com relação à avaliação do teor de lactose, verifica-se que houve diferença significativa $(\mathrm{P}<0,05)$ no teor de lactose para os diferentes tipos de suplementação, em que os teores de lactose foram maiores no leite dos animais que receberam concentrado proteico-energético. Os animais que receberam concentrado proteico tiveram o menor teor de lactose. Provavelmente 
isso ocorreu em razão da elevada contagem de células somáticas (CCS) no leite. Segundo Bueno et al. (2005), a correlação entre o CCS e a concentração de lactose é de $-0,42$, sendo forte essa correlação, o que leva à constatação de que $17,64 \%$ das variações do teor de lactose são decorrentes de variações na CCS.

Os animais que receberam suplementação proteico-energética tiveram maior teor de extrato seco desengordurado (ESD) $(\mathrm{P}<0,05)$ em relação aos demais (Tab. 6). Dessa forma, esse tipo de suplementação poderia ser mais apropriado para o período das águas em razão do equilíbrio dietético. A elevação dos teores de ESD é de grande interesse para indústrias lácteas, pois este resulta em maior rendimento de produtos.

As suplementações proteica e proteico-energética aumentaram a excreção de ureia no leite $(\mathrm{P}<0,05)$ em comparação às dietas com sal mineral e suplementação energética (Tab. 6). Os teores de ureia no leite para as dietas com suplementação proteica e proteico-energética são considerados altos quando comparados ao recomendado por Broderick e Clayton (1997), que consideraram como normal teor de até 18mg/dL. Segundo Linn e Olson (1995), concentrações de ureia no leite superiores a $18 \mathrm{mg} / \mathrm{dL}$ e teor de proteína do leite acima de $3,2 \%$ representariam excesso de proteína PDR/PNDR em relação ao consumo de carboidratos fermentáveis e energia líquida. Dessa forma, infere-se que, para as suplementações proteica e proteico-energética, há um excesso de proteína degradável no rúmen em relação à disponibilidade de energia, dada pela maior porcentagem de ureia e pela menor porcentagem de milho nos suplementos concentrados. Isso pode ser verificado na relação NDT/PB de 4,41 e 4,75, respectivamente, abaixo da relação 5,29 verificada na suplementação energética. A deficiência de carboidratos não fibrosos, principalmente as frações A e B1, que possuem maior taxa de degradação ruminal e quando há problemas na sua fermentação, há estagnação de todo o processo fermentativo no rúmen, aumenta os produtos indesejáveis, como amônia, a qual entra na rota metabólica de formação da ureia no leite (Leão et al., 2014).

De acordo com Souza et al. (2015), há sempre que se preocupar com o efeito do NUL (nitrogênio ureico no leite) sobre a eficiência reprodutiva das vacas. Nesse sentido, Butler (1998) verificou que teor de NUL acima de $19 \mathrm{mg} / \mathrm{dL}$ ocasionou redução da concentração plasmática de progesterona, bem como alteração do $\mathrm{pH}$ do ambiente uterino, e relacionou alteração desses parâmetros como as principais causas de redução da fertilidade em vacas no início da lactação. Contudo, Beserra et al. (2009) observaram que teor de NUL de até $26 \mathrm{mg} / \mathrm{dL}$ não afetou a eficiência reprodutiva de vacas Girolandas.

\section{CONCLUSÃO}

A suplementação proteico-energético de vacas leiteiras mantidas em pastagem de Tifton 85, sob manejo de pastejo em lotação contínua, mostrouse mais eficiente por maior resposta produtiva, marginal e econômica.

\section{AGRADECIMENTOS}

À Fapemig, pelo financiamento do projeto CVZ - APQ-01735-12.

\section{REFERÊNCIAS}

ALMEIDA, E.X.; MARASCHIN, G.E.; HARTHMANN, O.E.L. et al. Oferta de forragem de capim-elefante anão 'mott' e o rendimento animal. Rev. Bras. Zootec., v.29, p.1288-1295, 2000.

BARGO, F.; MULLER, L.D.; KOLVER, E.S. et al. Invited review: production and digestion of supplemented dairy cows on pasture. J. Dairy Sci., v.86, p.1-42, 2003.

BESERRA, E.E.A.; VIEIRA, R.J.; SOUZA, J.A.T. et al. Efeito do nitrogênio ureico no leite sobre a eficiência reprodutiva de vacas da raça Girolando. Rev. Cient. Prod. Anim., v.11, p.34-45, 2009.

BORGES, A.L.C.C.; TEIXEIRA, R.M.A.; SILVA, E.A. et al. Desempenho nutricional de bovinos leiteiros. Inf. Agropecu., v.36, p.88-99, 2015.

BRODERICK, G.A.; CLAYTON, M.K. A statistical evaluation of animal and nutritional factors influencing concentrations of milk urea nitrogen. $J$. Dairy Sci., v.80, p.2964-2971, 1997.

BUENO, V.F.F.; MESQUITA, A.J.; NICOLAU, E.S. et al. Contagem celular somática: relação com a composição centesimal do leite e período do ano no estado de Goiás. Ciênc. Rural, v.35, p.848-854, 2005.

BUTLER, W.R. Effect of protein nutrition on ovarian and uterine physiology in dairy cattle. J. Dairy Sci., v.81, p.2533-2539, 1998 . 
COSTA, V.A.C.; DETMANN, E.; PAULINO, M.F. et al. Consumo e digestibilidade em bovinos em pastejo durante o período das águas sob suplementação com fontes de compostos nitrogenados e de carboidratos. Rev. Bras. Zootec., v.40, p.1788-1798, 2011.

DETMANN, E.; PAULINO, M.F.; MANTOVANI, H.C.; VALADARES FILHO, S.C.; et al. Parameterization of ruminal fibre degradation in lowquality tropical forage using MichaelisMenten kinetics. Livest. Sci., v.126, p.136-146, 2009.

DETMANN, E.; PAULINO, M.F.; ZERVOUDAKIS, J.T. et al. Cromo e indicadores 19 internos na estimação do consumo de novilhos mestiços, suplementados, a pasto. Rev. Bras. Zootec., v.30, p.1600-1609, 2001.

DETMANN, E.; VALADARES FILHO, S.C.; PAULINO, M.F.; HUHTANEN, P. Nutritional aspects applied to grazing cattle in tropics: a review based on Brazilian results. Semin. Ciênc. Agrár., v.35, p.28292854, 2014a.

DETMANN, E.; VALENTE, E.E.L.; BATISTA, E.D.; HUHTANEN, P. An evaluation of the performance and efficiency of nitrogen utilization in cattle fed tropical grass pastures with supplementation. Livest. Sci., v.162, p.141-153, 2014b.

FERREIRA, D.F. Sisvar: a computer statistical analysis system. Ciênc. Agrotec., v.35, p.1039-1042, 2011.

FIGUEIRAS, J.F.; DETMANN, E.; VALADARES FILHO, S.C.; PAULINO, M.F. et al. Desempenho nutricional de bovinos em pastejo durante o período de transição seca-águas recebendo suplementação proteica. Arch. Zootec., v.64, p.269-276, 2015.

GOMIDE, J.A. Fatores da produção de leite a pasto. In: CONGRESSO NACIONAL DOS ESTUDANTES DE ZOOTECNIA, 1998, Viçosa. Anais... Viçosa: Conez, 1998, p.1-32.

LEÃO, G.F.M.; NEUMANN, M.; ROZANSKI, S. et al. Nitrogênio uréico no leite: aplicações na nutrição e reprodução de vacas leiteiras. Agropecu. Cient. Semiárido. v.10, p.29-36, 2014.

LICITRA, G.; HERNANDEZ, T.M.; VAN SOEST, P.J. Standardization of procedures for nitrogen fractionation of ruminant feeds. Anim. Feed Sci. Tec., v.57, p.347-358, 1996

LINN, J.G.; OLSON, J.D. Using milk urea nitrogen to evaluate diets and reproductive performance of dairy cattle. In: STATE APPLIED NUTRICION AND MANAGEMENT, 4., 1995, Wisconsin. Proceedings...Wisconsin: [s.n.], 1995. p.155-167.
NUTRIENT requirements of dairy cattle. 7.ed. Washington: National Academy of Sciences, 2001. 381p.

OLIVEIRA, A.S. Uso do conceito de análise marginal para estimar o nível ótimo de suplementos para bovinos. In: LANA, R.P. (Ed.). Respostas animais $e$ plantas aos nutrientes. Viçosa: UFV, 2015. p.155-171.

OLIVEIRA, A.S.; CAMPOS, J.M.S.; LANA, R.P. et al. Estimate of optimal level of concentrates for dairy cows on tropical pastures by using the concept of marginal analyses. Rev. Bras. Zootec., v.39, p.20402047, 2010.

OLIVEIRA, L.O.F.; SANTOS, S.A.; ABREU, U.G.P. et al. Uso de Indicadores nos estudos de nutrição animal aplicados aos sistemas de produção a pasto. Corumbá: Embrapa Pantanal, 2012. 24p.

PALMQUIST, D.L.; BEAULIEU, A.D.; BARBANO, D.M. Feed and animal factors influencing milk fat composition. J. Dairy Sci., v.76, p.1753-1771, 1993.

REEVER, M.; FULKERSON, W.J.; KELLAWAY, R.C. Production responses of dairy cows grazing wellmanaged kikuyu pastures to energy and protein supplementation. Aust. J. Exp. Agric., v.36, p.763-770, 1996

SANTOS, F.A.P.; MARTINEZ, J.C.; GRECO, L.F. et al. Nutrição de vacas em lactação, no período chuvoso, para a produção intensiva de leite em pasto. Cad. Téc. Vet. Zootec. v.57, p.1-39, 2008.

SILVA, D.J.; QUEIROZ, A.C. Análise de alimentos (métodos químicos e biológicos). Viçosa: UFV, 2002. 235p.

SKLAN, D.; ASHKENAZI, R.; BRAUN, A. et al. Fatty acids, calcium soaps of fatty acids and cottonseeds fed to high yielding cows. J. Dairy Sci., v.75, p.2463-2472, 1992.

SNIFFEN, C.J.; O'CONNOR, J.D.; VAN SOEST, P.J. et al. A net carbohydrate and protein system for evaluating cattle diets: II. Carbohydrate and protein availability. J. Anim. Sci., v.70, p.3562-3577, 1992.

SOUZA, R.C.; REIS, R.B.; LOPEZ, F.C.F. et al. Efeito da adição de teores crescentes de ureia na canade-açúcar em dietas de vacas em lactação sobre a produção e composição do leite e viabilidade econômica. Arq. Bras. Med. Vet. Zootec., v.67, p.564$572,2015$. 